\title{
Pengelolaan Daya Tarik Wisata Budaya Pura Puseh Pura Desa, Desa Pekraman Batuan, Gianyar
}

Ni Wayan Eka Suryaningsih a, 1, Saptono Nugroho a, 2

1ekadespar@gmail.com, 2saptono_nugroho@unud.ac.id

a Program Studi S1 Destinasi Pariwisata, Fakultas Pariwisata,Universitas Udayana, Jl. Dr. R. Goris, Denpasar, Bali 80232 Indonesia

\section{Abstract}

"Pura Puseh Pura Desa" keeps safely the inheritance things and its histories in the past. In addition, the existence of unique spiritual rituals of Batuan people as cultural attraction will support the development of "Pura Puseh Pura Desa" become a cultural tourism which is managed by elitist of Batuan village.

This research is located in Batuan village, Gianyar regency. The type of data in this research is qualitative data. The data source obtained from primary and secondary data. The method of this research is descriptive qualitative data that collected through through interviews, observation, and documentation. The determination of informant used purposive sampling.

The result of this research shows that "Pura Puseh Pura Desa" become an attracttion of cultural tourism which is managed by elite as the representative of Batuan village. The managed "Pura Puseh Pura Desa" by doing function of management such as planning, organization, actuating, controlling.

\section{Keyword: Management of tourist attraction, elite, Pura Puseh Pura Desa, cultural tourism}

\section{PENDAHULUAN}

Bali sebagai pariwisata budaya mulai difokuskan pengembangan dan pembangunannya pada orde baru yang dipersiapkan untuk mendukung kepariwisataan pada era tersebut. Masing-masing daerah mulai digali potensinya untuk dapat dikembangkan yang secara langsung dan diharapkan akan membantu pertumbuhan masyarakat lokal dengan terbukanya lapangan kerja baru.

Kabupaten Gianyar sebagai salah satu kabupaten yang kaya potensi wisata didukung dengan kemahiran Putra-Putri Gianyar dalam bidang kesenian sehingga banyak memiliki seniman dan maestro hebat yang dikenal bahkan sampai ke Mancanegara menyebabkan Gianyar dijuluki sebagai "kota seni". Gianyar dengan julukan kota seni juga dikembangkan sebagai wisata budaya karena memiliki sejarah yang dilengkapi dengan benda-benda purbakala sebagai daya tarik wisata. Benda-benda purbakala tersebut disimpan ditempat-tempat yang berbeda seperti Pura dan museum ataupun rumah raja zaman dulu. Namun, hanya beberapa lokasi yang telah dipublikasikan untuk umum seperti Pura Puseh Pura Desa, Desa Pakraman Batuan.

Pura Puseh Pura Desa sebagai tempat arkeologi tepat dikunjungi untuk melihat benda-benda peninggalan serta sejarah-sejarah masa lampau. Ditambah adanya ritual keagamaan yang unik oleh masyarakat Desa Pakraman Batuan sebagai atraksi budaya sangat mendukung pengembangan Pura Puseh Pura Desa, Desa Pakraman Batuan sebagai wisata budaya. Pengembangan Pura Puseh Pura Desa sebagai daya tarik wisata dilakukan oleh perwakilan dari masyarakat adat selaku pengempon pura. Setiap keputusan masih diputuskan oleh masyarakat adat hanya saja pelaksanaan pengelolaan dilakukan oleh pengurus adat sebagai elit desa.

Dalam pengelolaan yang dilakukan secara elitis di Pura Puseh Pura Desa sangat diperlukan fungsi-fungsi manejemen meliputi perencanaan, pengorganisasian, penggerakkan dan pengawasan yang baik oleh elit desa agar dapat tetap menjaga kesakralan dan kesucian Pura tersebut. Oleh karena itu, dalam penelitian ini akan membahas tentang elit dalam pengelolaan daya tarik wisata budaya di Pura Puseh dan Pura Desa, Desa Pakraman Batuan. Adapun tujuan dari penelitian ini adalah untuk mengetahui elit dalam pengelolaan daya tarik wisata budaya di Pura Puseh dan Pura Desa, Desa Pakraman Batuan.

\section{TINJAUAN PUSTAKA}

Penelitian sebelumnya dilakukan oleh $\mathrm{Ni}$ Wayan Surina, Ida Bagus Nyoman Wartha (2014) yang berjudul "Pura Puseh, Pura Desa Batuan Dalam Perkembangan Kepariwisataan Bali Di Desa Batuan Kecamatan Sukawati 
Kabupaten Gianyar". Kesimpulan yang diperoleh dari penelitian tersebut adalah bahwa fungsi pura meskipun dijadikan tempat pariwisata masih tetap dijaga kesakralannya, daya tarik yang ditawarkan di Pura Puseh Pura Desa adalah berupa sejarah dan peninggalan purbakala serta kegiatan kepariwisataan tersebut memberi dampak yang luar biasa terutama pada dampak ekonomi. Kegiatan kepariwisataan memberikan dampak positif bagi krama desa sebagai penyungsung pura dimana dana yang terkumpul dipakai untuk upacara yadnya renovasi, pembangunan pelinggih, biaya keamanan dan kebersihan di pura tersebut, sehingga krama desa tidak perlu lagi mengeluarkan dana wajib untuk kegiatan upacara. Dalam penelitian ini dengan penelitian sebelumnya memiliki kesamaan lokasi di Pura Puseh Pura Desa, Desa Pakraman Batuan. Namun, dengan focus penelitian yang berbeda karena penelitian sebelumnya meneliti tentang dampak kegiatan pariwisata di Pura Puseh Pura Desa, Desa Batuan bagi masyarakat dan penelitian ini terfokus pada pengelolaan yang dilakukan oleh elit desa di Pura Puseh Pura Desa, Desa Batuan.

\section{Landasan Konsep}

a. Konsep Daya Tarik Wisata

Konsep Daya Tarik Wisata menggolongkan atraksi menjadi empat yaitu atraksi alam, atraksi budaya, atraksi sosial, atraksi dalam bentuk bangunan (Yoeti, 2002). Adapun atraksi dalam penelitian ini adalah atraksi budaya dengan relief purbakala serta ritual keagamaan yang dilakukan secara turun temurun hingga saat ini.

b. Konsep Pengelolaan

Pengelolaan adalah pemanfaatan sumber daya manusia ataupun sumber daya lainnya yang dapat diwujudkan dalam kegiatan perencanaan, pengorganisasian, pergerakkan, dan pengawasan (R. Terry, 2006). Dalam penelitian ini konsep pengelolaan digunakan untuk mengetahui bagaimana pihak pengelola dalam mengaplikasikan fungsi-fungsi manajemen tersebut untuk keberlangsungan daya tarik wisata Pura Puseh Pura Desa Desa Pakraman Batuan.

c. Konsep Elit

Elit dalam pariwisata perdesaan adalah individu atau kelompok yang mempunyai kapasitas membangun relasi sosial berdasarkan pengalamannya sehingga dapat menentukan perkembangan destinasi pariwisata perdesaan (Adikampana, 2015a). Elit dibagi dua yaitu elit inklusive dan ekslusive. Elit inklusive dengan ciri-ciri partisipatif, visioner, legitimatif. Sedangkan ekslusive ciri-cirinya dominatif, pragmatis, non-legitimatif (Adikampana, 2015).

\section{METODE}

Penelitian ini dilakukan di Pura Puseh Pura Desa, Desa Pakraman Batuan, Kecamatan Sukawati, Gianyar. Adapun ruang lingkup penelitian yang digunakan yaitu: Pengelolaan daya tarik wisata budaya yang meliputi perencanaan, pengorganisasian, penggerakkan, dan pengawasan.

Data primer dalam penelitian ini diperoleh dari hasil observasi dan wawancara yang dilakukan peneliti di lapangan dengan menggunakan alat bantu rekam untuk mengetahui gambaran umum serta pengelolaan yang dilakukan oleh elit. Sedangkan data sekunder dalam penelitian ini diperoleh dari arsip Desa Pakraman Batuan. Teknik pengumpulan data yang digunakan dalam penelitian ini adalah observasi, wawancara dan dokumentasi.

Dalam penelitian ini peneliti melakukan observasi untuk mengetahui pelayanan yang diberikan kepada wisatawan dan kegiatan yang dilakukan oleh wisatawan. Adapun teknik wawancara yang digunakan adalah teknik wawancara semi terstruktur, artinya pewawancaralah yang lebih mengarahkan pembicaraan dan tidak mengajukan pertanyaan berdasarkan daftar pertanyaan yang telah disiapkan (Suwartono, 2014). Hal tersebut untuk mendapatkan informasi seluas-luasnya dari informan mengenai data pengelolaan yang dilakukan elite di daya tarik wisata. Dokumentasi yang digunakan pada penelitian ini adalah berupa foto-foto atraksi wisata dan kegiatan kepariwisataan oleh elit desa.

Teknik penentuan informan dalam penelitian ini menggunakan teknik purposive sampling. Adapun informan yang dipilih yaitu pengurus adat Desa Pakraman Batuan selaku pengelola Daya Tarik Wisata Pura Puseh Pura Desa yang dapat memberi informasi mengenai kepariwisataan di Daya Tarik Wisata Pura Puseh Pura Desa, Desa Pakraman Batuan.

Teknik analisis data yang digunakan dalam penelitian ini adalah analisis deskriptif 
kualitatif. Adapun langkah-langkahnya dalam analisis data dalam penelitian ini adalah sebagai berikut:

1. Reduksi Data

Reduksi dalam penelitian ini adalah data diperoleh dari hasil observasi, wawancara, serta dilengkapi dengan foto dipilih dan disesuaikan dengan topik dan tujuan penelitian ini. Datadata yang dimaksud adalah data pengelolaan daya tarik wisata budaya di Pura Puseh Pura Desa, Desa Pakraman Batuan

\section{Penyajian Data}

Penyajian data dilakukan dengan menyajikan data yang telah direduksi seperti hasil wawancara yang dituangkan ke dalam bentuk naratif didukung dengan gambar atraksi wisata Pura Puseh Pura Desa, Desa Pakraman Batuan.

3. Penarikan Kesimpulan

Kesimpulan dalam penelitian ini adalah data yang telah disajikan dalam bentuk teks dengan memperoleh poin-poin masing-masing ruang lingkup pembahasan. Kesimpulan yang diperoleh akan diverifikasikan sesuai topik hingga mencapai kredibel. Sehingga dapat menghasilkan data pengelolaan oleh elit desa yang di lakukan di Pura Puseh, Pura Desa, Desa Pakraman Batuan (Miles dan Huberman dalam Gunawan, 2015)

\section{HASIL DAN PEMBAHASAN}

Desa Pakraman atau disebut juga desa adat merupakan kesatuan wilayah tertutup atau terbatas pada pemujaan leluhur dan pengaturan administrasi masyarakat. Ada unsur kesatuan pura sebagai untur pengikat desa, yaitu: Pura Desa, Pura Puseh, dan Pura Dalem. Kesatuan pura ini oleh masyarakat Bali dikenal dengan Pura Kahyangan Tiga (Covarrubias dalam Arida, dkk, 2004). Jadi, menurut pengertian tersebut dapat diketahui bahwa dalam desa adat tersebut sudah pasti memiliki Pura Kahyangan Tiga dan diempon oleh masyarakat di desa adat tersebut. Desa adat memiliki pengurus adat yang bertanggung jawab dalam pelaksanaan kegiatan upacara agama khususnya di Pura Kahyangan Tiga. Ketiga Pura tersebut terletak terpisah-pisah. Namun, beberapa desa adat juga memiliki Pura Desa dan Pura Puseh yang berada pada satu tempat yang sama seperti misalnya Pura Puseh dan Pura Desa, Desa Pakraman Batuan.

Pura Puseh Pura Desa, Desa Pakraman Batuan disamping sebagai tempat pemujaan Sang Hyang Widhi juga merupakan tempat penyimpanan situs purbakala yang erat kaitannya dengan sejarah masa lampau. Selain itu masyarakat Desa Pakraman Batuan memiliki ritual keagamaan yang unik. Lokasi pura ini sangat strategis yaitu di jalur pariwisata maka beberapa wisatawan yang melewati jalur ini tertarik untuk berkunjung sampai akhirnya pengempon Pura membuka pura ini sebagai daya tarik wisata budaya.

Pengelolaan Pura Puseh Pura Desa dilakukan oleh para elit desa karena tidak adanya organisasi berupa kelompok sadar wisata (pokdarwis) atau kelompok khusus untuk membidangi secara khusus perkembangan pariwisata di daya tarik wisata Pura Puseh Pura Desa. Jadi untuk pelaksanaan kepariwisataan dilakukan oleh elit desa karena hal tersebut menyangkut tempat ibadah dan kesakralannya yang menjadi tanggung jawab elit desa sebagai perwakilan dari masyarakat untuk menjaganya. Dikelola oleh para elit secara inklusif dapat dilihat bahwa setiap perencanaan kegiatan sesuai dengan kesepakatan serta dukungan masyarakat, tidak bertentangan dengan budaya lokal dan aspirasi maupun kritik masyarakat sangat diterima dan dipertimbangkan sebaik-baiknya untuk dilaksanakan dalam pengelolaan di daya tarik wisata Pura Puseh Pura Desa, Desa Pakraman Batuan.

Berdasarkan hal tersebut, adapun pengelolaan Pura Puseh Pura Desa sebagai daya tarik wisata budaya berdasarkan fungsi manajemen yang dilakukan oleh pengurus adat Desa Pakraman Batuan adalah sebagai berikut:

1. Perencanaan meliputi:

a. Upaya pelestarian cagar budaya

Pelestarian cagar budaya di Pura Puseh Pura Desa dinilai sangat penting karena merupakan sebuah kegiatan yang bertujuan untuk menjaga kelestarian dan memperkenalkan benda-benda purbakala sebagai bukti sejarah kerajaan dimasa lampau agar tidak terabaikan. 
b. Upaya pelestarian seni dan budaya

Pura Puseh Desa, Desa Pakraman Batuan tetap berupaya untuk menjaga seni dan budaya yang telah diwariskan leluhur dibuktikan dengan tetap diadakan rentetan upacara sasih keenam sampai sasih kesanga yang menampilkan tarian rejang sutra yang dipentaskan mulai dari kalangan anak-anak sampai ibu-ibu, terdapat pula gambelan gambuh dan gocekan (sabung ayam). Semakin ditingkatkan pula pengadaan tari balih-balihan pada saat piodalan untuk menjaga keajegan seni dan budaya yang bersumber dari generasi muda Desa Pakraman Batuan.

c. Upaya pelestarian kesakralan dan kesucian Pura

Pura Puseh Desa, Desa Pakraman Batuan sebagai daya tarik wisata yang dikunjungi wisatawan dari berbagai negara akan tetapi nilai-nilai kesakralan dan kesucian Pura tetap dijaga dengan diadakan Upacara Tawur setiap perayaan hari besar Pura (piodalan). Kesucian pura juga dijaga dengan memajang papan pengumuman larangan-larangan masuk untuk orang yang tidak sedang datang bulan dan tidak mengenakan sarung.

d. Upaya peningkatan kualitas layanan

Untuk peningkatan kualitas layanan, pekerja khusus di Pura Puseh Pura Desa, Desa Pakraman Batuan mempersiapkan diri dengan bekal pengetahuan bahasa inggris untuk mempermudah komunikasi antara guest-host.

e. Upaya penyediaan sarana dan prasarana Adapun upaya untuk penyediaan sarana dan prasarana adalah dengan di sediakannya toilet umum, tambahan wantilan untuk tempat

Struktur Organisasi Pengurus Adat Desa Pakraman Batuan|

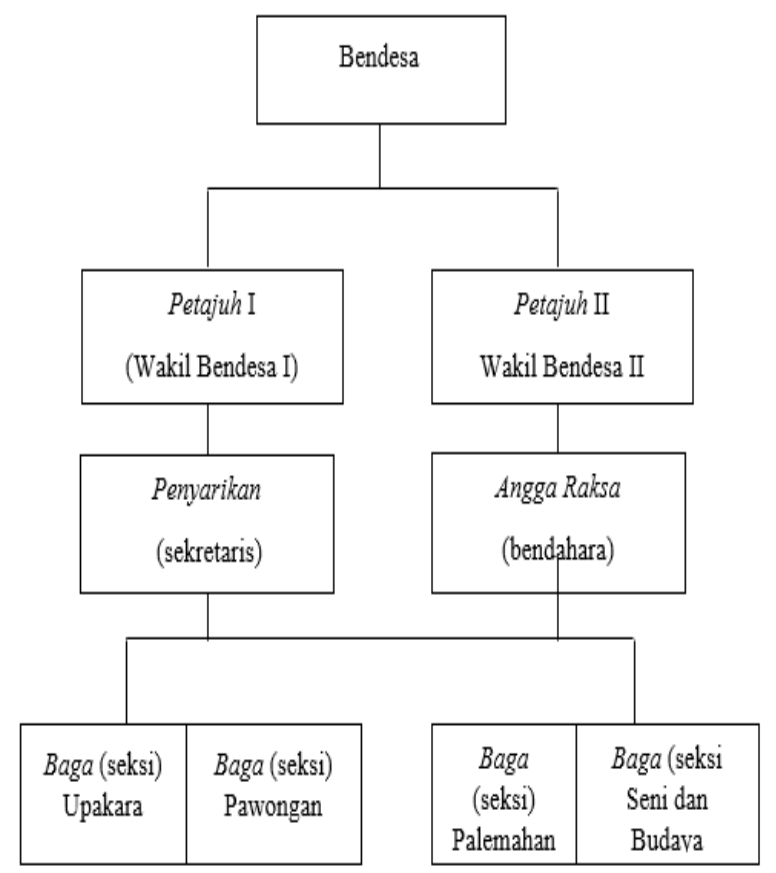

wisatawan beristirahat, areal parkir yang luas.

\section{Pengorganisasian}

Adapun penjabaran tugas dari masingmasing pengurus Desa Pakraman Batuan untuk pelaksanaan kepariwisataan di Pura Puseh Pura Desa antara lain:

a. Bendesa, bertanggung jawab untuk:

1. Mengkordinasikan aturan-aturan dengan pengurus-pengurus lainnya.

2. Mengawasi dan mengevaluasi hasil kerja seksi-seksi untuk pencapaian tujuan.

b. Petajuh I (wakil bendesa), bertanggung jawab untuk:

1. Bersama bendesa mengkordinasikan aturan-aturan dengan penguruspengurus lainnya.

2. Menggantikan bendesa apabila berhalangan hadir dalam setiap kegiatan.

c. Petajuh II (wakil bendesa II), bertanggung jawab untuk:

1. Bersama bendesa mengkordinasikan aturan-aturan dengan penguruspengurus lainnya.

2. Menggantikan tugas bendesa maupun petajuh I apabila berhalangan hadir.

d. Penyarikan (sekretaris), bertanggung jawab untuk:

1. Menyusun program kerja tahunan.

2. Mengurus surat menyurat yang diperlukan.

e. Angga Raksa (bendahara) bertanggung jawab untuk mencatat donasi dan bertanggung jawab atas hasil donasi Pura.

f. Baga (seksi) upakara bertanggung jawab atas kordinasi pelaksanaan upacara keagamaan.

g. Baga (seksi) pawongan bertanggung jawab untuk:

1. Bertanggung jawab atas kegiatan sosial masyarakat.

2. Menjaga harmonisasi antara wisatawan dengan masyarakat lokal. 
h. Baga (seksi) palemahan bertanggung jawab untuk:

1. Bertanggung jawab atas bagian fisik pura dan tata ruang pura.

2. Bertanggung jawab atas kondisi fisik situs purbakala.

i. Baga (seksi) seni dan budaya bertanggung jawab atas kelestarian seni dan budaya Desa Pakraman Batuan termasuk pengadaan kegiatan kesenian terhadap wisatawan.

3. Penggerakkan

a. Upaya pelestarian cagar budaya

Upaya pelestarian cagar budaya dilakukan dengan membuka Pura sebagai daya tarik wisata, memberi sign/peringatan kepada wisatawan untuk menjaga jarak agar tidak menyentuh benda-benda purbakala serta tetap memantau kegiatan wisatawan selama berada di area Pura.

b. Upaya pelestarian seni dan budaya

Pelestarian seni dan budaya di Pura Puseh Pura Desa, Desa Pakraman Batuan adalah dengan tetap mengadakan upacara rutin seperti tarian rejang, sambung ayam, dan gambelan gambuh pada sasih keenam sampai sasih kesanga atau dengan kurun waktu tiga bulan dalam kalender Bali.

c. Upaya pelestarian kesakralan dan kesucian Pura

Dengan mengadakan upacara Tawur Agung menggunakan tingkatan Uttama serta penyediaan sarung untuk wisatawan yang tidak membawa sarung. Sarung-sarung tersebut disediakan untuk wisatawan tanpa dipungut biaya serta kebersihan sarung pun dijaga dengan pencucian 3 hari sekali.

d. Upaya peningkatan kualitas layanan Berusaha untuk memberikan hak pekerja setara dengan hak yang telah ditentukan kabupaten agar dapat memberikan pelayanan prima kepada wisatawan,

e. Upaya penyediaan sarana dan prasarana Penambahan sebuah Wantilan terletak di barat pura untuk kegiatan tari-tarian yang akan disuguhkan kepada wisatawan, penyediaan toilet dan perluasan tempat parkir.

3. Pengawasan

Bendesa Desa Pakraman Batuan selaku pimpinan tertinggi di Desa Pakraman Batuan bertugas mengawasi dan memonitoring semua proses pengelolaan yang dilakukan di Pura Puseh Pura Desa, Desa Pakraman Batuan, mengevaluasi hasil kerja secara keseluruhan berdasarkan hasil kerja masing-masing seksi pengurus desa adat.

\section{SIMPULAN DAN SARAN}

Pengelolaan kepariwisataan tersebut dilakukan secara elitis yaitu oleh pengurus desa adat sebagai wakil masyarakat dengan tetap menjaga kesucian dan kesakralan Pura. Masingmasing pengurus telah memiliki job list dan menjalankan tugasnya sesuai dengan fungsifungsi manajemen seperti perencanaan, pengorganisasian, penggerakkan serta pengawasan telah dilakukan dengan baik. Untuk saran yang dapat diberikan terkait pengelolaan di Pura Puseh adalah perlu disediakan guest comment sebagai peningkatan kualitas layanan, diharapkan memiliki lembaga khusus sebagai pengelola kepariwisataan agar lebih fokus dan bekerja secara maksimal dalam pencapaian tujuan-tujuan masyarakat.

\section{Daftar Pustaka}

Adikampana. 2015. Paradigma dan Kebijakan Pariwisata. Denpasar: Cakra Press

Adikampana. 2015. Prosiding: Seminar Nasional Sains Dan Teknologi. Denpasar: Udayana University Press

Arida, Sukma \& dkk. 2004. Mengelola Konflik Batas Wilayah. Gianyar: Uluangkep Press

Gunawan, Imam.2015. Metode Penelitian Kualitatif. Jakarta: PT Bumi Aksara

R.Terry, George. 2006. Prinsip-Prinsip Manajemen. Jakarta: Bumi Aksara

Surina Ni Wayan, Nyoman Wartha Ida Bagus. 2014. Pura Puseh, Pura Desa Batuan Dalam Perkembangan Kepariwisataan Bali Di Desa Batuan Kecamatan Sukawati Kabupaten Gianyar(Kajian Pariwisata Budaya). Denpasar:

Suwartono. 2014. Dasar - Dasar Metodelogi Penelitian. Jakarta: Andi Offset

Yoeti, Oka A. 2002. Perencanaan StrategisPemasaran Daerah Tujuan Wisata. Jakarta: Pradnya Paramita 